\title{
Synthesis, Characterization, and Photocatalytic Tests of N-Doped Zinc Oxide: A New Interesting Photocatalyst
}

\author{
Chiara Gionco, Debora Fabbri, Paola Calza, and Maria Cristina Paganini \\ Dipartimento di Chimica, Università di Torino, Via P. Giuria 7, 10125 Torino, Italy \\ Correspondence should be addressed to Paola Calza; paola.calza@unito.it
}

Received 16 March 2016; Revised 13 May 2016; Accepted 31 May 2016

Academic Editor: Amjad Shraim

Copyright (C) 2016 Chiara Gionco et al. This is an open access article distributed under the Creative Commons Attribution License, which permits unrestricted use, distribution, and reproduction in any medium, provided the original work is properly cited.

\begin{abstract}
Fast and simple synthetic methods for the preparation of bare and $\mathrm{N}$-doped zinc oxide, involving a stirring or microwave assisted process, are proposed. All samples were characterized by XRD analysis, BET, and DRS-UV-Vis spectroscopy. The photocatalytic activity of these nanostructured oxides was investigated using phenol and 2,4-dichlorophenol as model molecules under UV-A and visible light irradiation. $\mathrm{N}$-doping in $\mathrm{ZnO}$ nanostructures provided a significant increase in phenol and 2,4-dichlorophenol degradation rate under Vis light, leading to a degradation rate higher than that obtained with bare $\mathrm{ZnO}$. The release of chlorine as chloride ions from 2,4-dichlorophenol with $\mathrm{N}$-doped $\mathrm{ZnO}$ was faster achieved as well and complete dechlorination was reached within $2 \mathrm{~h}$ of irradiation ( $\mathrm{N}$-doped $\mathrm{ZnO}$ ) instead of $3 \mathrm{~h}$ (bare $\mathrm{ZnO}$ ).
\end{abstract}

\section{Introduction}

A growing interest toward zinc oxide has arisen, due to its broad range of properties, that is, conductivity, high transparency, piezoelectricity, semiconducting broadband, ferromagnetism at room temperature, magnetic and optical properties, and sensitivity to the chemical species. Additional and particularly attractive features comprise $\mathrm{ZnO}$ stability to high-energy radiation, suggesting it as a prime candidate for space applications [1], and $\mathrm{ZnO}$ susceptibility to chemical attack (etching) in acidic or basic aqueous solutions, which provides the possibility to produce small size devices [2]. Even if studies began in the thirties and culminated in early eighties [3,4], later the interest gradually waned, due to the failure in the synthesis of p-type doped $\mathrm{ZnO}$. Actually, its direct band gap $(3.37 \mathrm{eV})$ and large exciton binding energy $(60 \mathrm{meV})$ [5] make this material one of the most promising functional materials for application in photocatalysis and solar cells production [6, 7]. However, owing to this large band gap, the role of doping tuning and controlling the electronic, magnetic, and optical properties of this solid was a key problem [8]; $\mathrm{ZnO}$ usually exhibits n-type behavior due to shallow donor impurities $[9,10]$. The latest developments in the field of doping and in the possibility to synthesize $\mathrm{ZnO}$ in different nanostructured forms make all these applications a concrete goal and convey a renewed interest toward $\mathrm{ZnO}$ research. Recently, a synthetic procedure was reported to obtain rare-earth doped $\mathrm{ZnO}$ nanomaterials that can be applied in many technologies, such as degradation of pollutants and optoelectronic devices [11-16].

Among dopant agents, nitrogen is emerging as a key dopant element in different semiconductor oxides. Considering $\mathrm{TiO}_{2}$, it has been one of the most promising candidates in the development of effective photocatalysts capable of operating efficiently under solar energy irradiation [17-19]. Recently Di Valentin and Pacchioni proposed an interesting comparison between different defective semiconductor oxides and nitrogen-doped oxides; $\mathrm{N}$-doped $\mathrm{TiO}_{2}, \mathrm{ZnO}$, and $\mathrm{WO}_{3}$ were presented as some of the most interesting materials [20].

In the case of $\mathrm{ZnO}$, the incorporation of $\mathrm{N}$ atoms in the oxide lattice is an effective approach to achieve p-type doping of this material; Klingshirn proved that $\mathrm{N}$ impurities act as shallow acceptors in $\mathrm{ZnO}$ thin films and bulk crystals [21].

So far, $\mathrm{N}$ impurities in $\mathrm{ZnO}$ were obtained by direct synthesis via chemical vapor deposition (CVD) methods in $\mathrm{N}_{2} \mathrm{O}$ or $\mathrm{NH}_{3}$ atmosphere [22], by mechanochemical methods $[23,24]$ or by postsynthesis treatments with $\mathrm{NH}_{3}$ at high 
temperature [25-27]. $\mathrm{N}$-doped $\mathrm{ZnO}$ has been proved to be a good photocatalyst in water oxidation [28] and in the degradation of rhodamine B [29].

In this work, we present two new synthetic strategies to prepare zinc oxide and nitrogen-doped zinc oxide, based on microwave assisted or stirring method. We tested the efficiency of these materials on two model molecules, phenol (P) and 2,4-dichlorophenol (2,4-DCP), under UV light and visible light, obtaining interesting results. In most studies $\mathrm{P}$ has been used as a molecule probe for photocatalytic tests, whose degradation mechanism is well established [30-33]. The choice of 2,4-DCP as additional model molecule is due to the fact that (a) it is an endocrine disrupting agent, widely used as herbicide, whose presence was detected in surface waters in several countries [34, 35], (b) it is highly soluble in water relative to other polychlorinated phenols, and (c) its simple molecular structure facilitates a greater understanding of the reaction mechanism involving aromatic compounds.

\section{Materials and Methods}

2.1. Materials and Reagents. Phenol, 2,4-dichlorophenol, catechol, 1,4-benzoquinone, resorcinol, hydroquinone, and all reactants employed in this work were purchased from Aldrich. Acetonitrile (AC0331 Supergradient HPLC grade eluent) was purchased from Scharlau. All aqueous solutions were prepared with ultrapure water Millipore Milli- $\mathrm{Q}^{\mathrm{TM}}$. All reactants employed in the synthesis processes, namely, $\mathrm{ZnSO}_{4} \cdot 7 \mathrm{H}_{2} \mathrm{O}$, ethylenediamine, ammonia, zinc acetate, and ethanol, were purchased from Aldrich and used without any further purification treatment.

2.2. Synthesis of $\mathrm{ZnO}$ and $\mathrm{N}-\mathrm{ZnO}$. Zinc oxide was synthesized following two different approaches. The first synthetic approach to produce bare $\mathrm{ZnO}$ involved a simple stirring process, adapted from [36]. Zinc acetate (2.2 g) and ethylenediamine $(0.6 \mathrm{~mL})$ were dissolved in $15 \mathrm{~mL}$ of ethanol. The solution was then stirred for 2 hours and dried at $50^{\circ} \mathrm{C}$ overnight and calcined at $500^{\circ} \mathrm{C}$ for two hours.

Nitrogen-doped $\mathrm{ZnO}$ was synthesized by adding to the mother solution urea $(0.6 \mathrm{~g})$ and ethanol $(15 \mathrm{~mL})$ and the resulting mixture was kept under stirring until a stable sol was obtained. The sol was dried at $50^{\circ} \mathrm{C}$ overnight and calcined at $500^{\circ} \mathrm{C}$ for two hours. These samples will be hereafter labeled as $\mathrm{ZnO}$ _St and N-ZnO_St.

The second method involved a microwave assisted precipitation process adapted from [37]: few drops of ammonia were added to a $0.25 \mathrm{M}$ aqueous solution of $\mathrm{ZnSO}_{4} \cdot 7 \mathrm{H}_{2} \mathrm{O}$ until the $\mathrm{pH}$ is 7 and a white precipitate appeared. The solution was stirred and heated in a domestic microwave oven $(2.45 \mathrm{GHz}$ and $800 \mathrm{~W}$ ) for $1 \mathrm{~min}$. $\mathrm{N}-\mathrm{ZnO}$ sample was synthesized with the same procedure, adding $0.25 \mathrm{~g}$ of urea to the starting aqueous solution of $\mathrm{ZnSO}_{4} \cdot 7 \mathrm{H}_{2} \mathrm{O}$. Then, the product (for both samples) was centrifuged at $6000 \mathrm{rpm}$ for $10 \mathrm{~min}$ and washed twice with deionized water. Both samples were dried at $50^{\circ} \mathrm{C}$ for 2 days and later calcined at $500^{\circ} \mathrm{C}$ for 2 hours. These samples will be hereafter labeled as $\mathrm{ZnO}$ _MW and $\mathrm{N}$ $\mathrm{ZnO}$-MW.
2.3. Characterization of Samples. Powder X-rays diffraction (XRD) patterns were recorded with a PANalytical PW3040/60 X'Pert PRO MPD using a copper $K_{\alpha}$ radiation source $(0.15418 \mathrm{~nm})$. The intensities were obtained in the $2 \theta$ ranges between $20^{\circ}$ and $70^{\circ}$. The X'Pert High-Score software was used for data handling. Rietveld refinement was performed on the diffraction patterns to determine the crystallite size and relative abundance of phases, using the MAUD 2.26 software and NIST Si powder to determine the instrumental function [38].

The surface area measurements were carried out on a Micromeritics ASAP 2020/2010 apparatus using the Brunauer-Emmett-Teller (BET) model for $\mathrm{N}_{2}$ adsorption measurements. Prior to the adsorption run, all of the samples were outgassed at $473 \mathrm{~K}$ for $3 \mathrm{~h}$.

The UV-Vis absorption spectra were recorded using a Varian Cary 5 spectrometer, coupled with an integration sphere for diffuse reflectance studies, using a Carywin-UV/ scan software. A sample of PTFE with $100 \%$ reflectance was used as reference.

2.4. Irradiation Procedures. Phenol and 2,4-dichlorophenol were used as model molecules to investigate the photocatalytic efficiency of zinc oxide based materials. Preliminary, we evaluate the stability of the materials at different $\mathrm{pHs}$. $\mathrm{pH}$ was adjusted using $\mathrm{HClO}_{4} 0.1 \mathrm{M}$ or $\mathrm{NaOH} 0.1 \mathrm{M}$. The $\mathrm{pH}$ range of stability was established to be $5-8$. The irradiation experiments were carried out in Pyrex glass cells filled with $5 \mathrm{~mL}$ of organic compound $\left(20 \mathrm{mgL}^{-1}\right)$ and catalyst $\left(1 \mathrm{gL}^{-1}\right)$. The irradiation was performed by using a TL K05 UV/A lamp $25 \mathrm{~mW} / \mathrm{m}^{2}$ centered at $365 \mathrm{~nm}$. Experiments using visible light only were performed in a devise equipped with a 1500 watt Xenon lamp (CO.FO.MEGRA, Milan, Italy) furnished with a $400 \mathrm{~nm}$ cut-off filter. The temperature reached during the irradiation was $30 \pm 2^{\circ} \mathrm{C}$. In all cases, experiments were run without modifying the natural $\mathrm{pH}$ of the solution. The entire content of the cells was then filtered through $0.45 \mu \mathrm{m}$ HA cellulose acetate membrane to remove $\mathrm{ZnO}$ particles and further analyzed by the appropriate analytical technique. Adsorption in the dark was assessed and was negligible for all materials. All experiments were performed in triplicate and the average results are plotted in the graphs. The stability of the material over prolonged irradiation time (24 and $48 \mathrm{~h}$ under UV-A lamp) was tested as well. The efficiency of preirradiated material is described in Section 3.2.

2.5. Analytical Determinations. The disappearance of the model molecule and the formation of transformation products as a function of the irradiation time were followed using an HPLC system (Merck-Hitachi L-6200 pumps), equipped with a Rheodyne injector, a RP C18 column (Lichrochart, Merck, $12.5 \mathrm{~cm} \times 0.4 \mathrm{~cm} ; 5 \mu \mathrm{m}$ packing), and a UV-Vis detector (Merck-Hitachi L-4200) set at $220 \mathrm{~nm}$. Elution was carried out with acetonitrile and phosphate buffer $(1 \times$ $\left.10^{-2} \mathrm{M}\right)$ at $\mathrm{pH} 2.8(40: 60 \% \mathrm{v} / \mathrm{v})$ at a flow rate of $1 \mathrm{~mL} / \mathrm{min}$.

Chloride formation was evaluated by a Dionex ion chromatograph equipped with a conductometer detector, using a AS9HC anionic column and a buffer solution composed by 


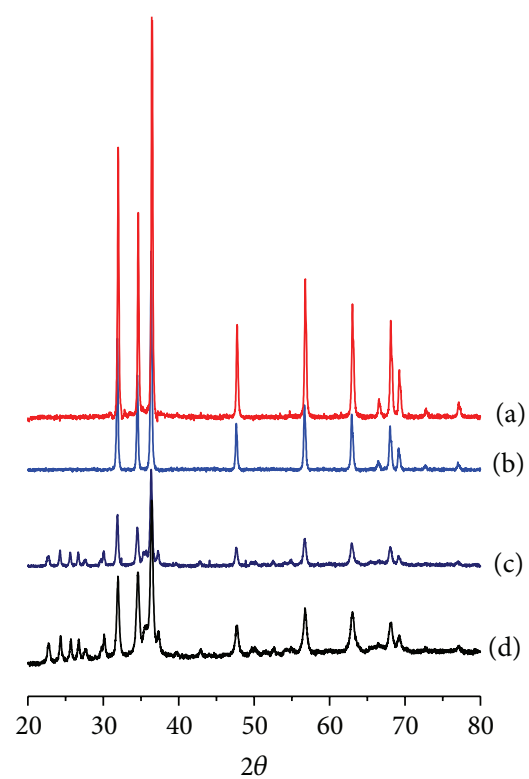

FIgURE 1: XRD patterns for (a) ZnO_St, (b) N-ZnO_St, (c) ZnO_MW, and (d) N-ZnO_MW.

$\mathrm{NaHCO}_{3} 11 \mathrm{mM}$ and $\mathrm{K}_{2} \mathrm{CO}_{3} 4.5 \mathrm{mM}$ as eluent at a flow rate of $1 \mathrm{~mL} / \mathrm{min}$. In these experimental conditions, the retention time for chloride ion was $5.30 \mathrm{~min}$.

\section{Results and Discussion}

3.1. Materials Characterization. XRD patterns for the synthetized samples are shown in Figure 1. The diffraction peaks of bare (Figure 1 lines (a) and (c)) and doped (Figure 1 lines (b) and (d)) materials are attributable to the (1 000$),\left(\begin{array}{lll}0 & 0 & 2\end{array}\right),\left(\begin{array}{ll}1 & 0\end{array}\right.$ 1), (1 02 2), (1 110$),\left(\begin{array}{lll}1 & 0 & 3\end{array}\right),\left(\begin{array}{lll}2 & 0 & 0\end{array}\right),\left(\begin{array}{lll}1 & 1 & 2\end{array}\right)$, and (2 01 ) planes which are in accordance with the wurtzite hexagonal phase of $\mathrm{ZnO}$ [18]. These patterns are similar to all samples, assessing that neither the introduction of nitrogen nor the diverse synthesis changes the crystal structure of $\mathrm{ZnO}$ [36].

The samples obtained using zinc sulphate as precursor (i.e., those obtained with the microwave assisted method) also show additional peaks attributable to zinc oxysulphate that did not evolve properly during the synthesis process. On the XRD patterns a Rietveld refinement was performed using the MAUD software that allowed estimating the average size of the crystallites. These values are about 70 and $40 \mathrm{~nm}$ for $\mathrm{ZnO} \mathrm{MW}$ and $\mathrm{N}-\mathrm{ZnO}$ _MW nanostructures and 136 and $107 \mathrm{~nm}$ for ZnO_St and $\mathrm{N}-\mathrm{ZnO}$ _St samples, respectively. Regardless of the synthetic method employed, the insertion of dopant caused a decrease in the crystallites size; this phenomenon was already observed and reported in the literature $[39,40]$.

The specific surface area of the samples was measured applying the Brunauer-Emmett-Teller (BET) model on $\mathrm{N}_{2}$ adsorption measurement. Samples produced through the stirring method (ZnO_St and N-ZnO_St) exhibited a surface area of less than $10 \mathrm{~m}^{2} / \mathrm{g}$, while those synthetized through microwave assisted method (ZnO_MW and N-ZnO_MW) have a slightly higher area $\left(11.5 \pm 0.9 \mathrm{~m}^{2} / \mathrm{g}\right)$, underlining that the surface area is dependent on the synthetic method but is not affected by $\mathrm{N}$-doping. The unexpected low surface area obtained with these synthetic processes was quite surprising, considering the quite high photoactivity of that samples, but higher than the commercial $\mathrm{ZnO}$ powder $\left(4-5 \mathrm{~m}^{2} / \mathrm{g}\right)$ [41].

Figure 2 shows the absorption spectra (DRS UV-Vis) obtained for $\mathrm{ZnO}$ and $\mathrm{N}$-doped $\mathrm{ZnO}$ samples. Two main issues arose from these spectra:

(1) the optical properties of the bare materials prepared from different synthetic methods (stirring and microwave assisted) are very similar;

(2) the N-doping causes tiny modifications in the band gap (vide infra), but a high modification in the whole absorption spectra.

In particular, the optical spectra of bare $\mathrm{ZnO}$ (Figure 2 line (A) and (B)) are dominated by the valence band (VB) to conduction band (CB) transition occurring at about $400 \mathrm{~nm}$ (ca. $3 \mathrm{eV}$ ) and the two spectra exhibit relatively small differences, in agreement with previous data reported in literature [36]. Figure 2 also compares the optical absorptions of N-doped zinc oxide (line (C) and (D)). A deep difference between doped and bare oxides spectra is evident. A large absorption in visible region of the optical spectra, together with a tiny red shift of the absorption edge $(0.03 \mathrm{eV}$, vide infra $)$, is observable. A small absorption shoulder centered at about $530 \mathrm{~nm}$ is more evident in Figure 2(b), where an enlargement of Figure 2(a) is provided. Doped samples show a pale grey-yellow color. The yellow is due to the presence of nitrogen into the structure (absorption band centered around 500-530 nm); the grey color is due to carbon impurities trapped into the structure during the calcination process (resulting in a tail in the absorption across the whole visible region).

The band gap of all the samples was calculated by linearization of the plot reporting $(\alpha h v)^{2}$ versus $h v$ typical of direct band gap transitions for $\mathrm{ZnO}$ and $\mathrm{Ce}-\mathrm{ZnO}$ through the Tauc plot from DRS measures [42]. Bare samples (namely, $\mathrm{ZnO}$ _St and $\mathrm{ZnO} O \mathrm{MW}$ ) show a band gap of $3.28 \mathrm{eV}$, while for $\mathrm{N}$-doped $\mathrm{ZnO}$ (namely, N-ZnO_St and N-ZnO_MW) it is $3.25 \mathrm{eV}$, implying that the doping process does not induce a modification in the material band gap. This behavior is not surprising and was already reported in the literature [36].

3.2. Photocatalytic Tests. The photocatalytic activity of all synthetized materials was firstly investigated using phenol as model molecule. Phenol is known to be scarcely adsorbed at the catalyst surface and its degradation mainly proceeds through an initial oxidative attack, with the formation of hydroxylated derivatives $[43,44]$. Preliminary tests showed that the direct photolysis process is very slow and can be considered negligible in the considered time window [45].

The curves of phenol abatement as a function of irradiation time are plotted in Figure 3 for $\mathrm{ZnO}$ _St and in Figure 4 for ZnO_MW. Under UV-A irradiation, the phenol disappearance similarly occurred with both bare and $\mathrm{N}$ doped $\mathrm{ZnO}$, irrespective of the synthetic method employed, and the complete disappearance is observed within $3 \mathrm{~h}$ of 


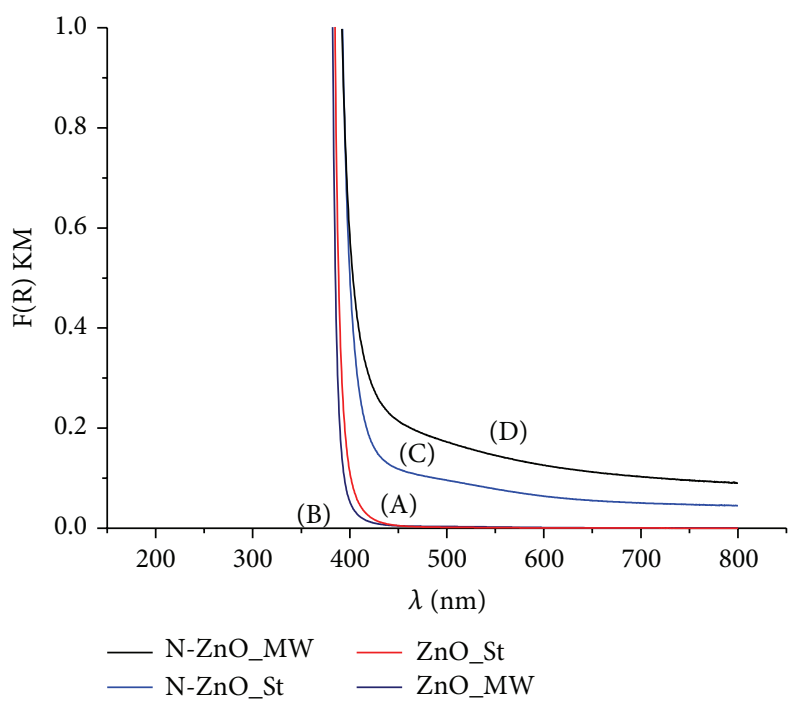

(a)

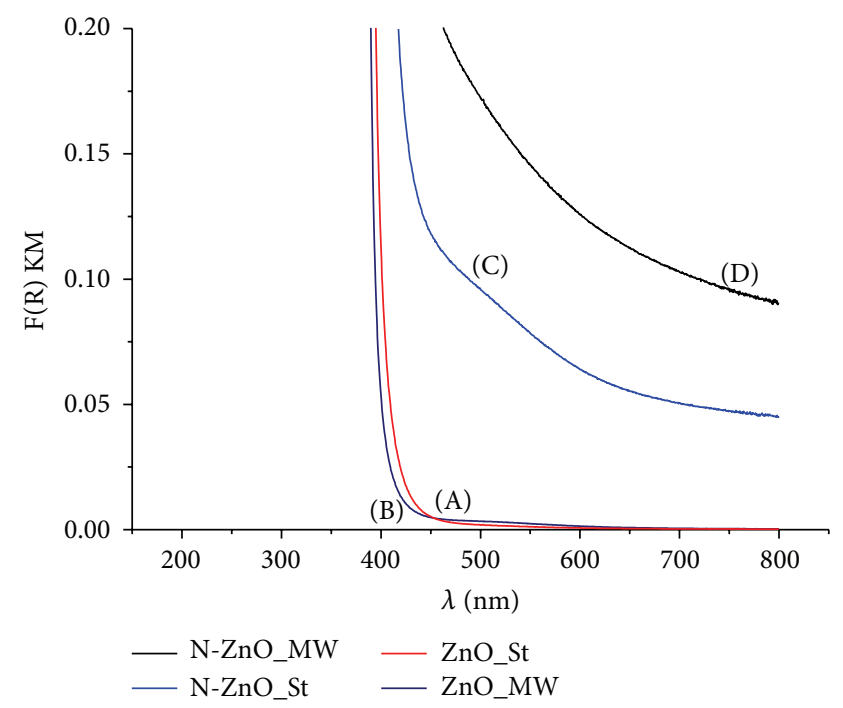

(b)

FIGURE 2: Kubelka-Munk transformed diffuse reflectance spectra of (a) (A) ZnO_St, (B) ZnO_MW, (C) N-ZnO_St, (D) N-ZnO_MW, and (b) their enlargement.

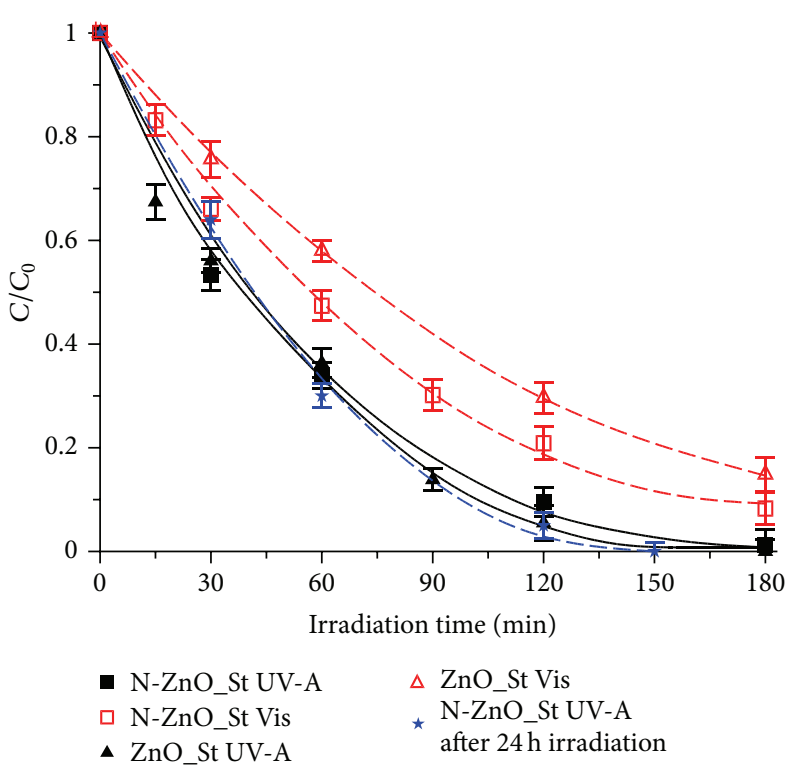

(a)

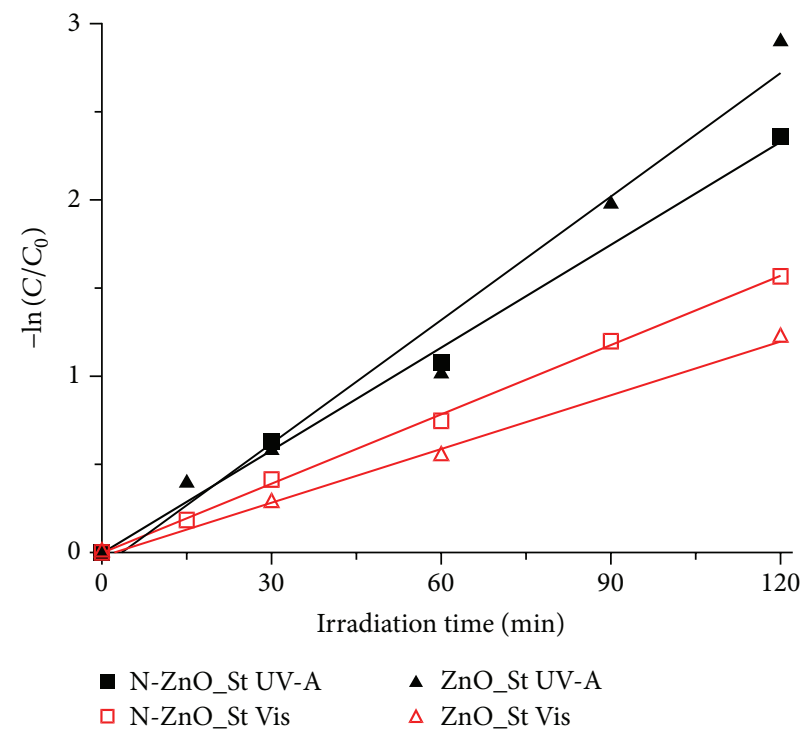

(b)

FIGURE 3: Disappearance of phenol $\left(20 \mathrm{mg} \mathrm{L}^{-1}\right)$ in the presence of bare $\mathrm{ZnO}$ _St and N-doped zinc oxide N-ZnO_St $\left(\mathrm{St}\right.$ method) (1 gL $\left.{ }^{-1}\right)$ under irradiation with UV-A or visible light.

irradiation. Conversely, under Vis light irradiation, phenol degradation rate is higher with $\mathrm{N}$-doped $\mathrm{ZnO}$ rather than with bare $\mathrm{ZnO}$.

Linear plots shown in left of Figures 3(a) and 4(a) were obtained by fitting the degradation data with

$$
-\ln \left(\frac{C}{C_{0}}\right)=k t
$$

where $C_{0}$ is initial concentration and $C$ is concentration measured after the irradiation time $t$; in all cases, a good
TABLE 1: Constant rate values calculated through (1).

\begin{tabular}{lcccc}
\hline$K$, min $^{-1}$ & ZnO_St & N-ZnO_St & ZnO_MW & N-ZnO_MW \\
\hline UV-A & $2.3 \times 10^{-2}$ & $1.9 \times 10^{-2}$ & $2.1 \times 10^{-2}$ & $1.5 \times 10^{-2}$ \\
Vis & $1.0 \times 10^{-2}$ & $1.3 \times 10^{-2}$ & $0.54 \times 10^{-2}$ & $0.76 \times 10^{-2}$ \\
\hline
\end{tabular}

linearity is observed. The calculated $k$ values are summarized in Table 1.

Considering materials synthesized with MW method under Vis, the half-time life $\left(t_{1 / 2}\right)$ was reduced from $130 \mathrm{~min}$ 


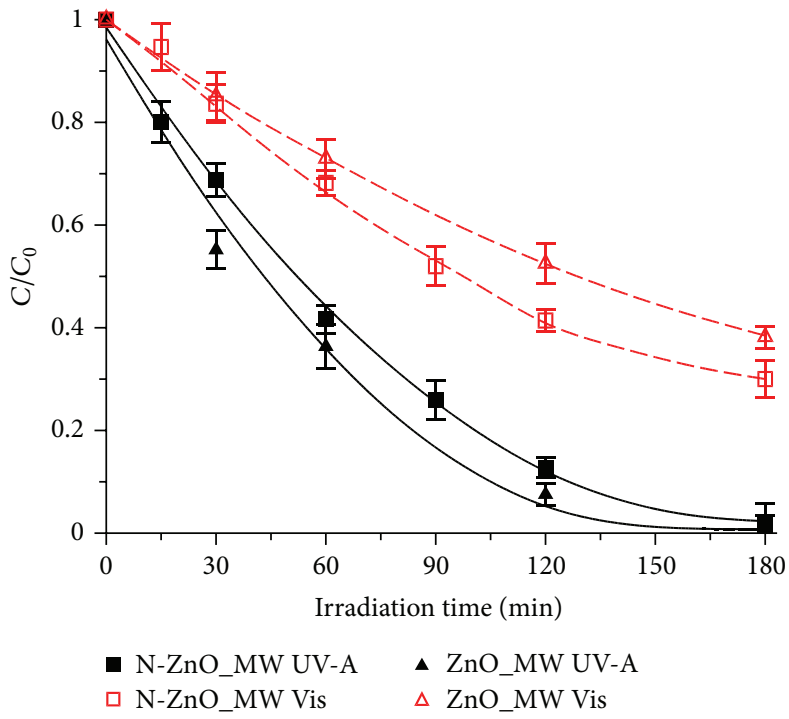

(a)

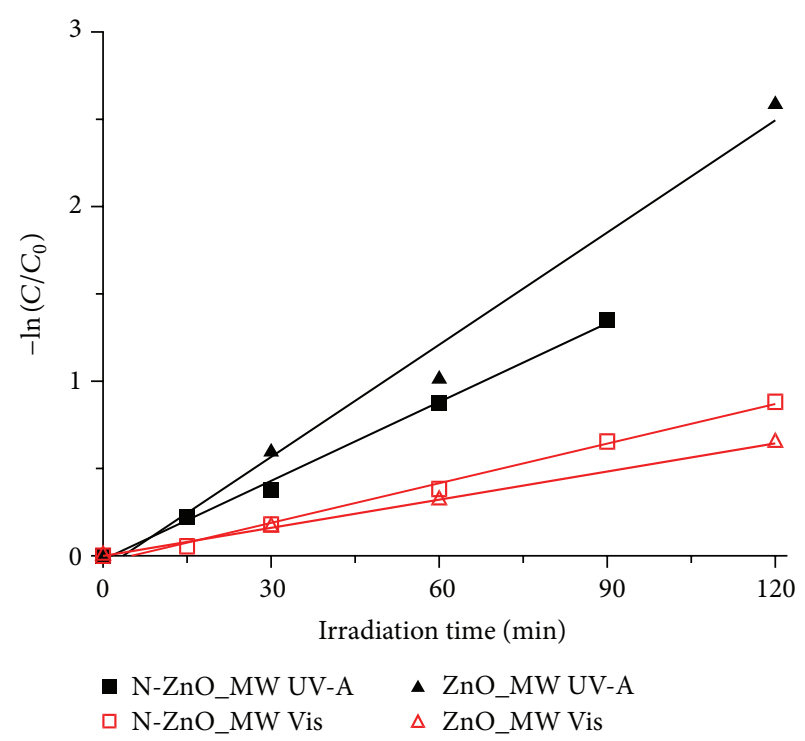

(b)

FIGURE 4: Disappearance of phenol $\left(20 \mathrm{mg} \mathrm{L}^{-1}\right)$ in the presence of bare (ZnO_MW) and N-doped zinc oxide (N-ZnO_MW) (MW method) $\left(1 \mathrm{gL}^{-1}\right)$ under irradiation with a UV-A or visible light.

$(\mathrm{ZnO})$ to $90 \mathrm{~min}(\mathrm{~N}-\mathrm{ZnO})$ and after $3 \mathrm{~h}$ of irradiation, almost $70 \%$ of phenol is abated, while with bare $\mathrm{ZnO}$ only $60 \%$ of phenol disappeared. Materials prepared through stirring method evidenced similar $t_{1 / 2}$ (almost $60 \mathrm{~min}$ ) and under Vis after $3 \mathrm{~h}$ of irradiation the percentage of degraded phenol passes from $85 \%$ (bare $\mathrm{ZnO}$ ) to $93 \%$ ( $\mathrm{N}$-doped $\mathrm{ZnO}$ ). The experiment is repeated toward the abatement of phenol by using the materials preirradiated for 24 and $48 \mathrm{~h}$ under UVA. Results show that the efficiency of the catalyst remains the same. As an example, the case of the phenol degradation with $\mathrm{N}-\mathrm{ZnO}$ _St is reported in Figure 3(a).

The photocatalytic increase observed with Vis light for $\mathrm{N}$-doped systems cannot be ascribed to a variation in the materials band gap but could be attributed to the pronounced shoulder showing the presence of intraband gap states and not to a real shift of the band gap itself [19].

The best performance was obtained with the materials prepared via stirring synthetic method. A possible explanation of this behavior could be the fact that the materials prepared via zinc acetate, as precursor, followed a better synthetic procedure and the final product was more clean and without defective compounds.

The performance of zinc oxide based materials produced via stirring method was also investigated toward the abatement of 2,4-dichlorophenol (2,4-DCP) under visible light. Once more, 2,4-DCP degradation faster occurred with $\mathrm{N}$ doped material and the complete degradation was achieved within $2 \mathrm{~h}$ of irradiation (Figure 5(a)). Chloride ions were easier released in the case of $\mathrm{N}$-doped material, too. The chloride evolution curve closely resembles the phenol disappearance curve. When employing $\mathrm{N}$-doped material, the formation of chloride ions in stoichiometric amount was achieved within $2 \mathrm{~h}$ of irradiation, while with bare $\mathrm{ZnO} 3 \mathrm{~h}$ is required. Following 2,4-DCP degradation, the formation of some transformation products occurred, whose identity was confirmed by injection of authentic standard solution. Their concentration over time is reported in Figure 5(b) and showed the formation of hydroquinone (HQ) as main transformation product in both cases, at a slight higher amount in the presence of $\mathrm{N}-\mathrm{ZnO}$; 4-chlorophenol (4-CP) was also detected but was formed at higher concentration with bare material. These results are well matched with the chloride ions evolution.

\section{Conclusions}

Microwave assisted method and a more classic stirring process were applied for preparation of bare and N-doped nanostructured zinc oxide, as a potential highly efficient photocatalyst. The degradation of phenol on these sample was followed using both UV-A and visible light.

UV light does not discriminate bare or doped materials but the irradiation with visible light evidenced the higher efficiency of doped materials compared to the bare oxides. This difference was also maintained in the chloride evolution, as with $\mathrm{N}$-doped materials 2,4-dichlorophenol dechlorination was easily achieved. This aspect is interesting in order to obtain materials whose photocatalytic activity is promoted by solar light.

\section{Competing Interests}

The authors declare that they have no competing interests.

\section{Acknowledgments}

This work has been supported by a Marie Curie International Research Staff Exchange Scheme Fellowship (PHOTOMAT, 


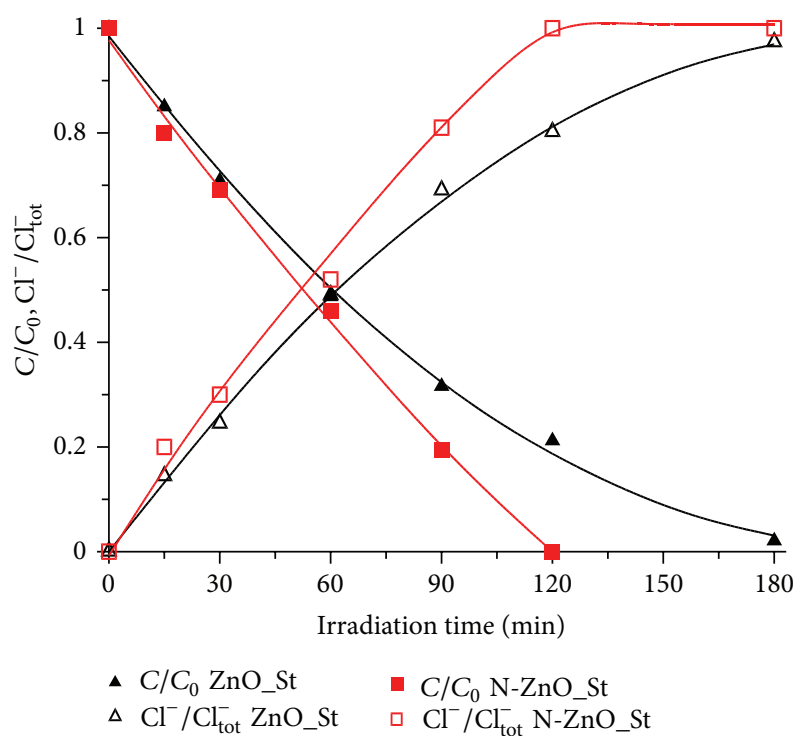

(a)

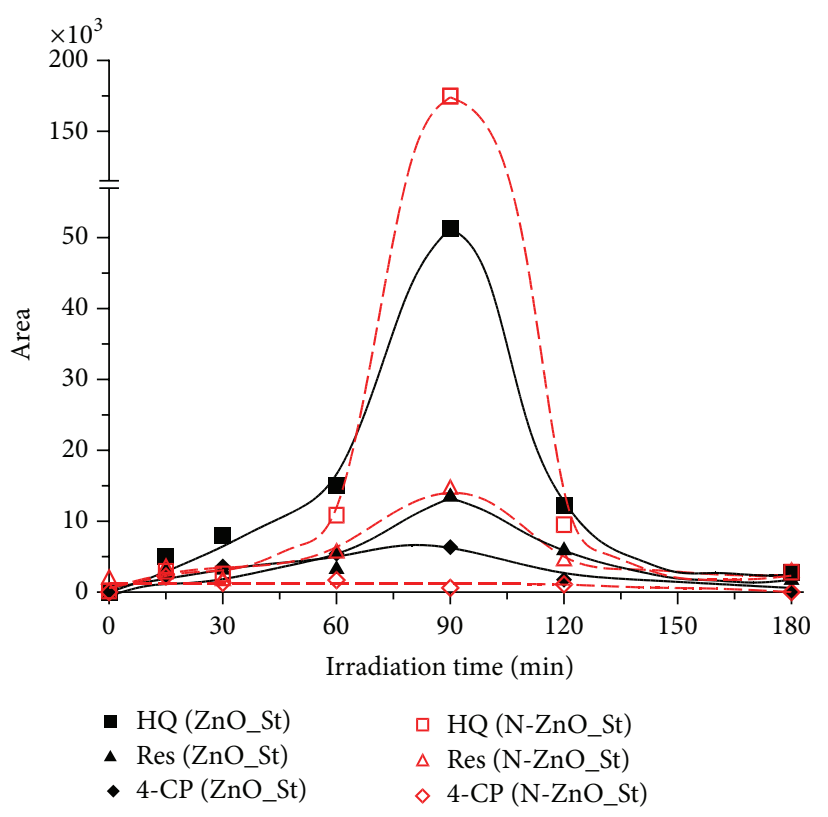

(b)

FIGURE 5: Disappearance of 2,4-dichlorophenol $\left(20 \mathrm{mg} \mathrm{L}^{-1}\right)$ and chloride evolution (a) and TPs formation (b) in the presence of bare and $\mathrm{N}$-doped zinc oxide (St method) N-ZnO_St $\left(\mathrm{gL}^{-1}\right)$ under visible light. Hydroquinone (HQ), resorcinol (Res), and 4-chlorophenol (4-CP) concentration over time are plotted.

Proposal no. 318899) within the 7th European Community Framework Programme and by Project MAT4TREAT within the European Union's Horizon 2020 Research and Innovation Programme under the Marie Skłodowska-Curie grant Agreement no, 645551. Local Funding of the University of Torino call_2014_L2_126 is also acknowledged.

\section{References}

[1] S. O. Kucheyev, J. S. Williams, C. Jagadish et al., "Ion-beamproduced structural defects in $\mathrm{ZnO}$," Physical Review B, vol. 67, no. 9, Article ID 094115, 2003.

[2] D. C. Look, "Recent advances in $\mathrm{ZnO}$ materials and devices," Materials Science and Engineering B: Solid-State Materials for Advanced Technology, vol. 80, no. 1-3, pp. 383-387, 2001.

[3] Z. Dong, X. Lai, J. E. Halpert et al., "Accurate control of multishelled $\mathrm{ZnO}$ hollow microspheres for dye-sensitized solar cells with high efficiency," Advanced Materials, vol. 24, no. 8, pp. 1046-1049, 2012.

[4] G. Heiland, E. Mollwo, F. Stockmann, S. Frederick, and T. David, "Electronic processes in zinc oxide," in Solid State Physics, pp. 191-323, Academic Press, 1959.

[5] M. H. Huang, S. Mao, H. Feick et al., "Room-temperature ultraviolet nanowire nanolasers," Science, vol. 292, no. 5523, pp. 1897-1899, 2001.

[6] M. H. Huang, S. Mao, H. Feick et al., "Room-temperature ultraviolet nanowire nanolasers," Science, vol. 292, no. 5523, pp. 1897-1899, 2001.

[7] J. Jiang, X. Zhang, P. Sun, and L. Zhang, " $\mathrm{ZnO/BiOI} \mathrm{heterostruc-}$ tures: photoinduced charge-transfer property and enhanced visible-light photocatalytic activity," Journal of Physical Chemistry C, vol. 115, no. 42, pp. 20555-20564, 2011.
[8] S. J. Pearton, D. P. Norton, K. Ip, Y. W. Heo, and T. Steiner, "Recent progress in processing and properties of $\mathrm{ZnO}$," Progress in Materials Science, vol. 50, no. 3, pp. 293-340, 2005.

[9] C. G. Van de Walle, "Hydrogen as a cause of doping in zinc oxide," Physical Review Letters, vol. 85, no. 5, pp. 1012-1015, 2000.

[10] S. F. J. Cox, E. A. Davis, S. P. Cottrell et al., "Experimental confirmation of the predicted shallow donor hydrogen state in zinc oxide," Physical Review Letters, vol. 86, no. 12, pp. 26012604, 2001.

[11] M. Rezaei and A. Habibi-Yangjeh, "Microwave-assisted preparation of Ce-doped $\mathrm{ZnO}$ nanostructures as an efficient photocatalyst," Materials Letters, vol. 110, pp. 53-56, 2013.

[12] T. M. Williams, D. Hunter, A. K. Pradhan, and I. V. Kityk, "Photoinduced piezo-optical effect in Er doped $\mathrm{ZnO}$ films," Applied Physics Letters, vol. 89, no. 4, Article ID 043116, 2006.

[13] C. Karunakaran, P. Gomathisankar, and G. Manikandan, "Preparation and characterization of antimicrobial Ce-doped $\mathrm{ZnO}$ nanoparticles for photocatalytic detoxification of cyanide," Materials Chemistry and Physics, vol. 123, no. 2-3, pp. 585-594, 2010.

[14] T.-Y. Ma, Z.-Y. Yuan, and Q. J.-L. Cao, "Hydrangea-like mesomacroporous $\mathrm{ZnO}-\mathrm{CeO}_{2}$ binary oxide materials: synthesis, photocatalysis and CO oxidation," European Journal of Inorganic Chemistry, no. 5, pp. 716-724, 2010.

[15] J.-C. Sin, S.-M. Lam, K.-T. Lee, and A. R. Mohamed, "Photocatalytic performance of novel samarium-doped spherical-like $\mathrm{ZnO}$ hierarchical nanostructures under visible light irradiation for 2,4-dichlorophenol degradation," Journal of Colloid and Interface Science, vol. 401, pp. 40-49, 2013.

[16] J.-C. Sin, S.-M. Lam, K.-T. Lee, and A. R. Mohamed, "Fabrication of erbium-doped spherical-like $\mathrm{ZnO}$ hierarchical nanostructures with enhanced visible light-driven photocatalytic activity," Materials Letters, vol. 91, pp. 1-4, 2013. 
[17] R. Asahi, T. Morikawa, T. Ohwaki, K. Aoki, and Y. Taga, "Visible-light photocatalysis in nitrogen-doped titanium oxides," Science, vol. 293, no. 5528, pp. 269-271, 2001.

[18] X. Chen and S. S. Mao, "Titanium dioxide nanomaterials: synthesis, properties, modifications, and applications," Chemical Reviews, vol. 107, no. 7, pp. 2891-2959, 2007.

[19] S. Livraghi, M. C. Paganini, E. Giamello, A. Selloni, C. Di Valentin, and G. Pacchioni, "Origin of photoactivity of nitrogen-doped titanium dioxide under visible light," Journal of the American Chemical Society, vol. 128, no. 49, pp. 15666-15671, 2006.

[20] C. Di Valentin and G. Pacchioni, "Spectroscopic properties of doped and defective semiconducting oxides from hybrid density functional calculations," Accounts of Chemical Research, vol. 47, no. 11, pp. 3233-3241, 2014.

[21] C. F. Klingshirn, "ZnO: material, physics and applications," ChemPhysChem, vol. 8, no. 6, pp. 782-803, 2007.

[22] K. Iwata, P. Fons, A. Yamada, K. Matsubara, and S. Niki, "Nitrogen-induced defects in $\mathrm{ZnO}: \mathrm{N}$ grown on sapphire substrate by gas source MBE," Journal of Crystal Growth, vol. 209, no. 2-3, pp. 526-531, 2000.

[23] S. Moribe, T. Ikoma, K. Akiyama, Q. Zhang, F. Saito, and S. Tero-Kubota, "EPR study on paramagnetic species in nitrogendoped $\mathrm{ZnO}$ powders prepared by a mechanochemical method," Chemical Physics Letters, vol. 436, no. 4-6, pp. 373-377, 2007.

[24] J. Lu, Q. Zhang, J. Wang, F. Saito, and M. Uchida, "Synthesis of $\mathrm{N}$-Doped $\mathrm{ZnO}$ by grinding and subsequent heating $\mathrm{ZnO}$-urea mixture," Powder Technology, vol. 162, no. 1, pp. 33-37, 2006.

[25] J. Sann, J. Stehr, A. Hofstaetter et al., "Zn interstitial related donors in ammonia-treated $\mathrm{ZnO}$ powders," Physical Review B: Condensed Matter and Materials Physics, vol. 76, no. 19, Article ID 195203, 2007.

[26] Z. Yu, L.-C. Yin, Y. Xie, G. Liu, X. Ma, and H.-M. Cheng, "Crystallinity-dependent substitutional nitrogen doping in $\mathrm{ZnO}$ and its improved visible light photocatalytic activity," Journal of Colloid and Interface Science, vol. 400, pp. 18-23, 2013.

[27] F. Gallino, C. Di Valentin, G. Pacchioni, M. Chiesa, and E. Giamello, "Nitrogen impurity states in polycrystalline $\mathrm{ZnO}$. A combined EPR and theoretical study," Journal of Materials Chemistry, vol. 20, no. 4, pp. 689-697, 2010.

[28] D. Zhang, J. Gong, J. Ma, G. Han, and Z. Tong, "A facile method for synthesis of $\mathrm{N}$-doped $\mathrm{ZnO}$ mesoporous nanospheres and enhanced photocatalytic activity," Dalton Transactions, vol. 42, no. 47, pp. 16556-16561, 2013.

[29] X. Zong, C. H. Sun, H. Yu et al., "Activation of photocatalytic water oxidation on $\mathrm{N}$-doped $\mathrm{ZnO}$ bundle-like nanoparticles under visible light," The Journal of Physical Chemistry C, vol. 117, no. 10, pp. 4937-4942, 2013.

[30] A. G. Agrios and P. Pichat, "Recombination rate of photogenerated charges versus surface area: opposing effects of $\mathrm{TiO}_{2}$ sintering temperature on photocatalytic removal of phenol, anisole, and pyridine in water," Journal of Photochemistry and Photobiology A: Chemistry, vol. 180, no. 1-2, pp. 130-135, 2006.

[31] S. Liu, N. Jaffrezic, and C. Guillard, "Size effects in liquidphase photo-oxidation of phenol using nanometer-sized $\mathrm{TiO}_{2}$ catalysts," Applied Surface Science, vol. 255, no. 5, pp. 2704-2709, 2008.

[32] C. Renzi, C. Guillard, J.-M. Herrmann, P. Pichat, and G. Baldi, "Effects of methanol, formamide, acetone and acetate ions on phenol disappearance rate and aromatic products in UVirradiated $\mathrm{TiO}_{2}$ aqueous suspensions," Chemosphere, vol. 35, no. 4, pp. 819-826, 1997.
[33] I. Arana, J. M. Dona-Rodriguez, E. T. Rendon et al., " $\mathrm{TiO}_{2}$ activation by using activated carbon as a support-part II. Photoreactivity and FTIR study," Applied Catalysis B: Environmental, vol. 44, no. 2, pp. 153-160, 2003.

[34] J. Gao, L. Liu, X. Liu, H. Zhou, S. Huang, and Z. Wang, "Levels and spatial distribution of chlorophenols - 2,4-Dichlorophenol, 2,4,6-trichlorophenol, and pentachlorophenol in surface water of China," Chemosphere, vol. 71, no. 6, pp. 1181-1187, 2008.

[35] S. Chiron, C. Minero, and D. Vione, "Occurrence of 2,4dichlorophenol and of 2,4-dichloro-6-nitrophenol in the Rhône River Delta (Southern France)," Environmental Science and Technology, vol. 41, no. 9, pp. 3127-3133, 2007.

[36] H. Qin, W. Li, Y. Xia, and T. He, "Photocatalytic activity of heterostructures based on $\mathrm{ZnO}$ and $\mathrm{N}$-doped $\mathrm{ZnO}$," ACS Applied Materials and Interfaces, vol. 3, no. 8, pp. 3152-3156, 2011.

[37] L.-C. Chen, Y.-J. Tu, Y.-S. Wang, R.-S. Kan, and C.-M. Huang, "Characterization and photoreactivity of N-, S-, and C-doped $\mathrm{ZnO}$ under UV and visible light illumination," Journal of Photochemistry and Photobiology A: Chemistry, vol. 199, no. 2-3, pp. 170-178, 2008.

[38] L. Lutterotti, "Total pattern fitting for the combined size-strainstress-texture determination in thin film diffraction," Nuclear Instruments and Methods in Physics Research, Section B: Beam Interactions with Materials and Atoms, vol. 268, no. 3-4, pp. 334340, 2010.

[39] C. Gionco, M. C. Paganini, S. Agnoli, A. E. Reeder, and E. Giamello, "Structural and spectroscopic characterization of $\mathrm{CeO}_{2}-\mathrm{TiO}_{2}$ mixed oxides," Journal of Materials Chemistry A, vol. 1, no. 36, pp. 10918-10926, 2013.

[40] S. Livraghi, F. Olivero, M. C. Paganini, and E. Giamello, "Titanium ions dispersed into the $\mathrm{ZrO}_{2}$ matrix: spectroscopic properties and photoinduced electron transfer," Journal of Physical Chemistry C, vol. 114, no. 43, pp. 18553-18558, 2010.

[41] X. Wang, L. Huang, Y. Zhao, Y. Zhang, and G. Zhou, "Synthesis of mesoporous $\mathrm{ZnO}$ nanosheets via facile solvothermal method as the anode materials for lithium-ion batteries," Nanoscale Research Letters, vol. 11, no. 1, article 37, 2016.

[42] G. Martra, E. Gianotti, and S. Coluccia, "The application of UVvisible-NIR spectroscopy to oxides," in Metal Oxide Catalysis, pp. 51-94, Wiley-VCH Verlag GmbH \& Co. KGaA, Weinheim, Germany, 2009.

[43] P. Calza, V. Maurino, C. Minero, E. Pelizzetti, M. Sega, and M. Vincenti, "Photoinduced halophenol formation in the presence of iron(III) species or cadmium sulfide," Journal of Photochemistry and Photobiology A: Chemistry, vol. 170, no. 1, pp. 61-67, 2005.

[44] C. Minero, G. Mariella, V. Maurino, and E. Pelizzetti, "Photocatalytic transformation of organic compounds in the presence of inorganic anions. 1. Hydroxyl-mediated and direct electrontransfer reactions of phenol on a titanium dioxide-fluoride system," Langmuir, vol. 16, no. 6, pp. 2632-2641, 2000.

[45] P. Calza, L. Rigo, and M. Sangermano, "Investigations of photocatalytic activities of photosensitive semiconductors dispersed into epoxy matrix," Applied Catalysis B: Environmental, vol. 106, no. 3-4, pp. 657-663, 2011. 

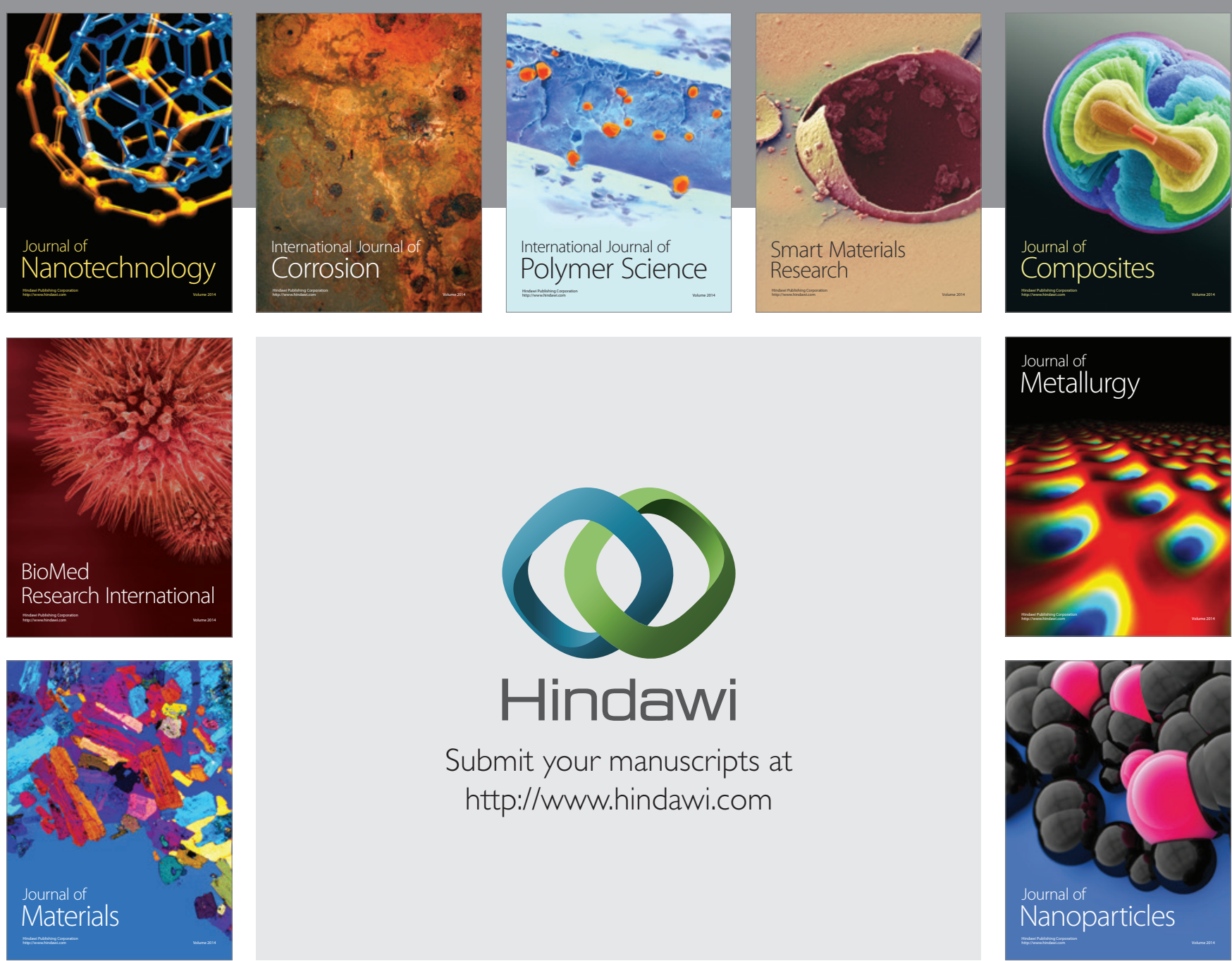

\section{Hindawi}

Submit your manuscripts at

http://www.hindawi.com

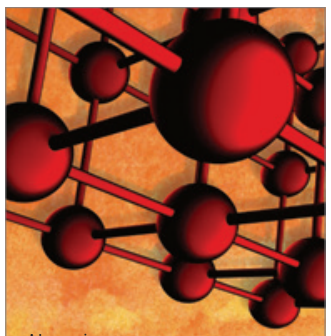

Materials Science and Engineering
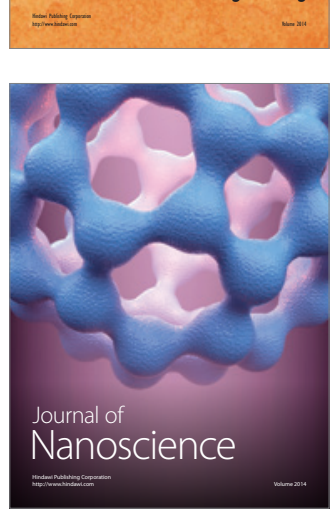
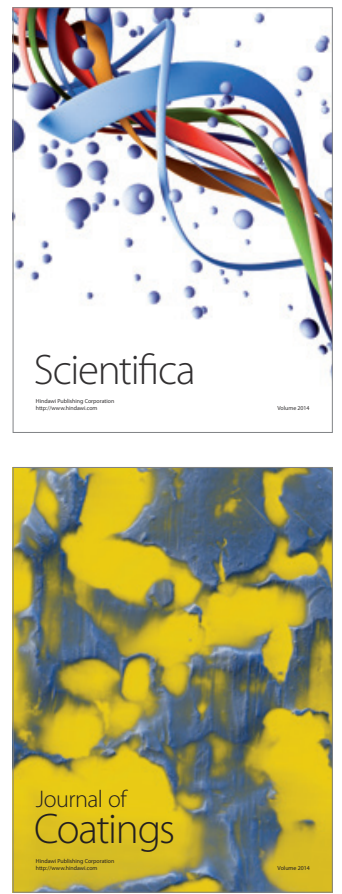
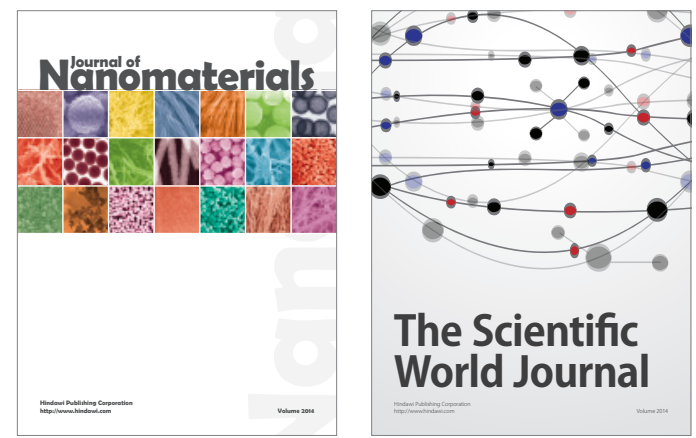

The Scientific World Journal
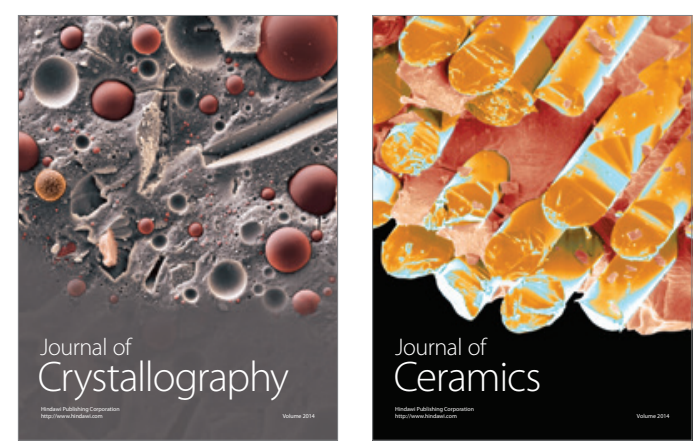
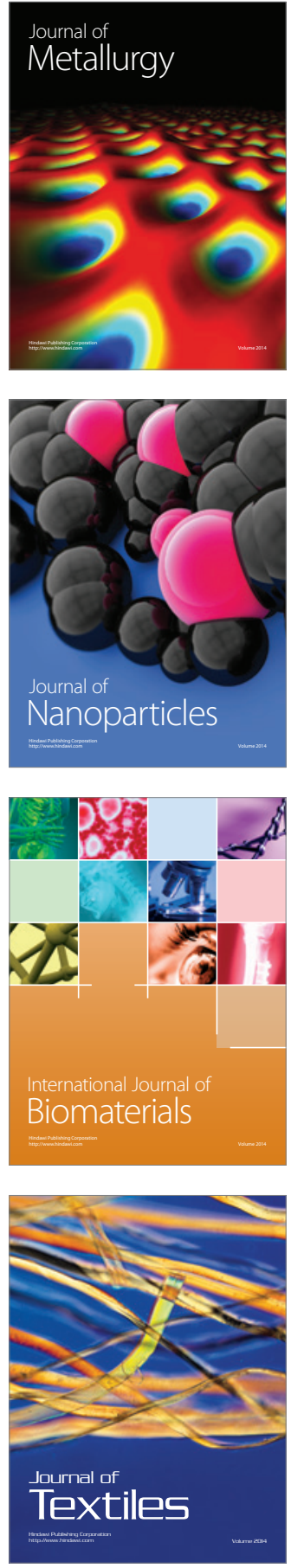